\title{
THE WENCKEBACH PHENOMENON AND AURICULAR-VENTRICULAR DISSOCIATION IN CHILDREN
}

\author{
BY \\ M. H. SHNIER \\ From the Department of Paediatrics, Baragwanath Hospital, Johannesburg
}

(RECEIVED FOR PUBLICATION NOVEMBER 26, 1957)

The Wenckebach type of heart block is characterized by a progressive lengthening of the P-R interval until A.V. conduction fails and a beat is dropped. This form of heart block was first described as a clinical entity by Wenckebach (1899) on the basis of radial arteriograms. Since then, this phenomenon has been seen in a variety of conditions including digitalis poisoning, rheumatic fever, tonsillitis and other febrile conditions, diphtheritic and other forms of myocarditis and myocardial infarction. It is not uncommon in adults but few case descriptions refer to children.

Sprague and White (1927), when describing cases of heart block under the age of 30 years, make brief reference to a group of children showing this phenomenon. They described a transient Wenckebach phenomenon in a girl aged 16 years following tonsillectomy and a post-operative cold and more severe grades of heart block in children suffering from diphtheria and rheumatic fever. Zimdahl (1951) and Kuhn, Donoso and Sapin (1954) each described the cases of two children in whom the Wenckebach phenomenon complicated cardiac catheterization. Langen (1956) reported the phenomenon in two 19-year-old youths in whom no cardiac lesion could be found. Ehrentheil, Alimurung and Massell (1952) on analysis of 107 electrocardiograms showed a relationship between sinus arrhythmia and the Wenckebach phenomenon.

A.V. dissociation exists when the auricles and ventricles beat independently. According to Wood (1946) this condition occurs when in nodal rhythm retrograde conduction is completely blocked while forward conduction remains unimpaired. As the rate of discharge from the sinus node is usually slower than that from the A.V. node, the ventricles beat faster than the auricles. Occasionally, however, the auricular rate may be the faster (Magri, 1953).

As in the Wenckebach phenomenon, rheumatic fever, diphtheria, acute febrile states, myocarditis and myocardial infarction may be associated with A.V. dissociation.
This paper presents the case histories of five children with cardiac arrhythmia. Two of these cases are examples of the Wenckebach phenomenon and three cases are examples of A.V. dissociation.

\section{Case Histories}

Case 1. A 4-year-old African child was in good health until five days before admission to hospital when she developed an irritating cough. Soon after this, diarrhoea and vomiting commenced associated with anorexia, fever, vague abdominal pains and headache.

Examination revealed a thin undernourished child. Her temperature was $103^{\circ} \mathrm{F}$. The pulse rate varied between 50 and 100 beats a minute and was unaffected by respiration. The volume was poor. The heart was not clinically enlarged and no murmurs were audible. The remainder of the clinical examination was essentially negative and the child was investigated as a case of pyrexia of unknown, possibly influenzal, aetiology.

An electrocardiogram recorded 12 hours after admission (Fig. 1a) shows the Wenckebach phenomenon (the first and last complexes) and 2:1 A-V block. This arrhythmia persisted for 96 hours with periods of 2:1 A-V block (Figs. 1b and 1c) and the classical Wenckebach phenomenon (Fig. 1c and 1d).

LABORATORY INVESTIGATIONS. The haemoglobin was $15.8 \mathrm{~g} . / 100 \mathrm{ml}$. with a leucocyte count of $9 \cdot 000 / \mathrm{c} . \mathrm{mm}$. (60\% neutrophil polymorphs, $6 \%$ monocytes, $29 \%$ lymphocytes, $5 \%$ eosinophils). The sedimentation rate was $50 \mathrm{~mm}$. per hour (Westergren). The serum sodium was $135 \mathrm{mEq} . / \mathrm{l}$. and the serum potassium was $5.7 \mathrm{mEq}$./l. No pathological organisms were found in the blood, stools or urine. Agglutination tests for typhoid fever and complement fixation tests for viral diseases were negative.

The fever abated 48 hours after admission but the child remained distressed until the fifth day of illness when she improved dramatically. This improvement coincided with a return to normal cardiac rhythm (Fig. 1e).

This patient was observed for a further two months during which period her electrocardiogram continued to show a normal rhythm (Fig. 1f).

Case 2. An African boy, aged 9 years, had been in good health until four days before admission to hospital. 


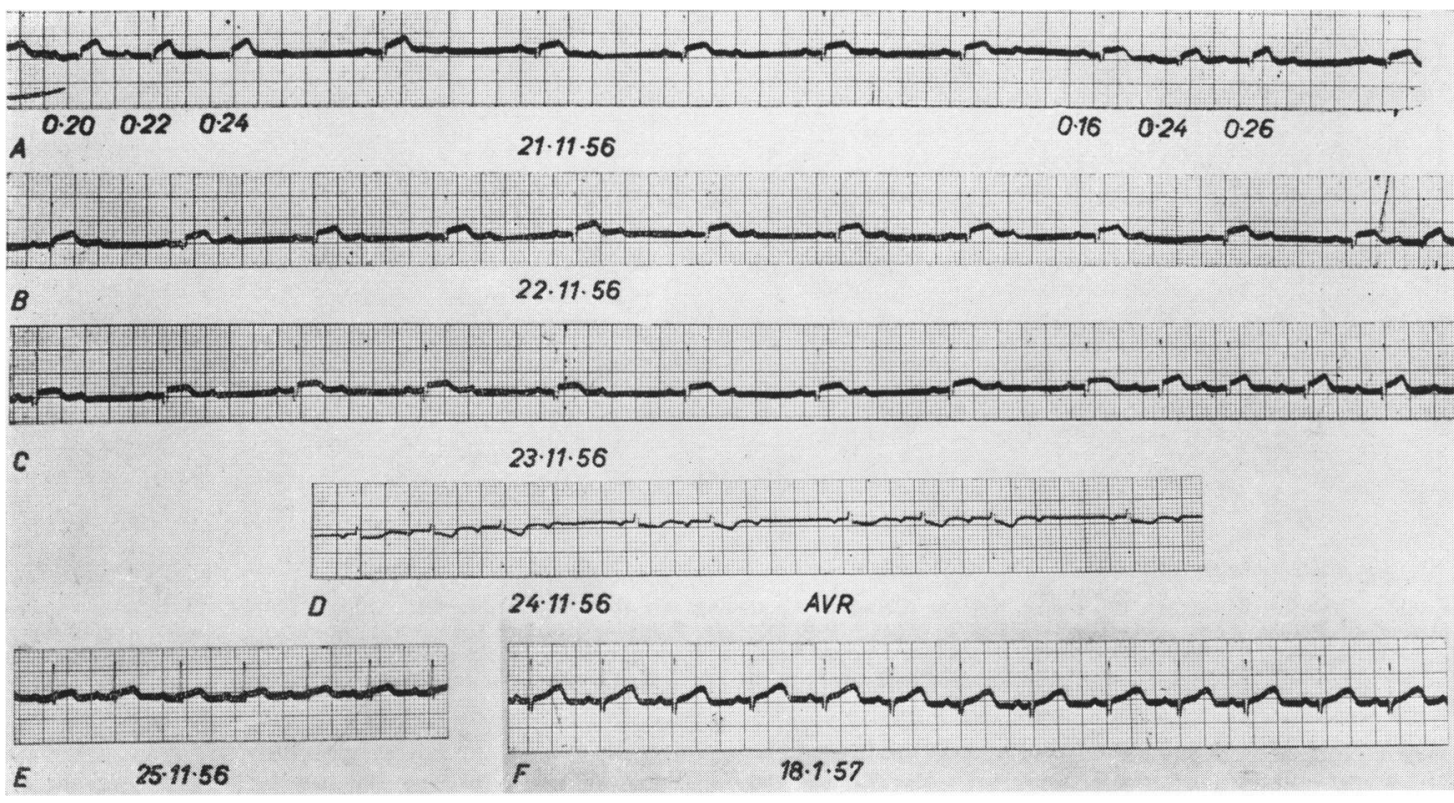

FIG. 1.-Case 1. Pyrexia of unknown, possibly influenzal, origin. Fig. 1a: (standard lead II) classical Wenckebach phenomenon tracing in the first and last three complexes with $2: 1$ A.V. block which may be considered as extreme form of this phenomenon. Fig. $1 \mathrm{~b}: 24$ hours later, a 2:1 A.V. block, which was unaltered the next day (Fig. 1c). Fig. 1d: (lead AVR) a day later, classical Wenckebach phenomenon tracing. Figs. le and 1f: normal tracings four days and two months after initial tracing.

He then developed pain in the chest accompanied by a severe cough productive of green mucoid sputum. He had also noticed increasing breathlessness and swelling of the feet.

Examination revealed a dyspnoeic child with dependent oedema to the level of the sacrum. The pulse rate was 120 beats a minute and the volume was full. The blood pressure was $100 / 75 \mathrm{~mm}$. $\mathrm{Hg}$. The maximum cardiac impulse was located in the 6th intercostal space over the anterior axillary line and suggested left ventricular hypertrophy. A grade III systolic murmur was heard at the mitral area replacing the first heart sound and was conducted into the axilla. The pulmonary second sound was slightly accentuated and clearly split. Crepitations were audible at the bases of both lungs. The liver was palpable 4 fingerbreadths below the costal margin.

LABORATORY INVESTIGATIONS. The haemoglobin was $15 \cdot 3 \mathrm{~g} . / 100 \mathrm{ml}$. with a leucocyte count of 7,800 per $\mathrm{c}, \mathrm{mm}$. (41\% neutrophil polymorphs, $4 \%$ monocytes, $55 \%$ lymphocytes). The E.S.R. was $8 \mathrm{~mm}$. per hour (Westergren), the antistreptolysin titre was $1 / 200$ units and the C reactive protein was ++++ . The diagnosis was acute rheumatic carditis with congestive cardiac failure.

During the first 12 hours the child received $1.0 \mathrm{mg}$. of digoxin orally divided into three doses given 4-hourly. During the next 12 hours he was given three doses of $0.125 \mathrm{mg}$. and thereafter was maintained on $0.125 \mathrm{mg}$. twice daily. In addition he was given a low salt diet and received a mercurial diuretic by intramuscular injection on alternate days. On this therapy his pulse rate slowed from 120 to 96 beats a minute. A month later he complained of nausea and vomiting and dropped beats were noticed. Digoxin was discontinued and potassium chloride $\mathrm{g}$. 3 daily was given by mouth. Three days later when cardiac failure was again apparent, digoxin therapy was recommenced without recurrence of the arrhythmia.

Electrocardiographic studies concomitant with the onset of nausea and vomiting (Fig. 2a) showed P-R intervals of 0.28 seconds with occasional dropped beats. The dropped beats occurred at random without lengthening of the preceding P-R intervals. The P-R intervals following a dropped beat were shortened to 0.24 seconds while the electrocardiograms recorded 24 and 72 hours later (Figs. $2 b$ and 2c) showed that the P-R intervals varied in length from 0.28 to 0.32 seconds before a dropped beat occurred.

A return to normal rhythm was recorded four days after the arrhythmia was first noted (Fig. 2d).

Case 3. A 9-year-old African boy had suffered, since the age of 6 years from repeated attacks of pain in the chest, back and feet with periodic swelling around the ankles. His exercise tolerance remained good until four weeks before admission to hospital, when breathlessness occurred on exertion. His symptoms gradually increased until he was immobilized by dyspnoea and a generalized swelling of his whole body.

On examination the child was dyspnoeic with dependent oedema to the level of the sacrum. The jugular veins 


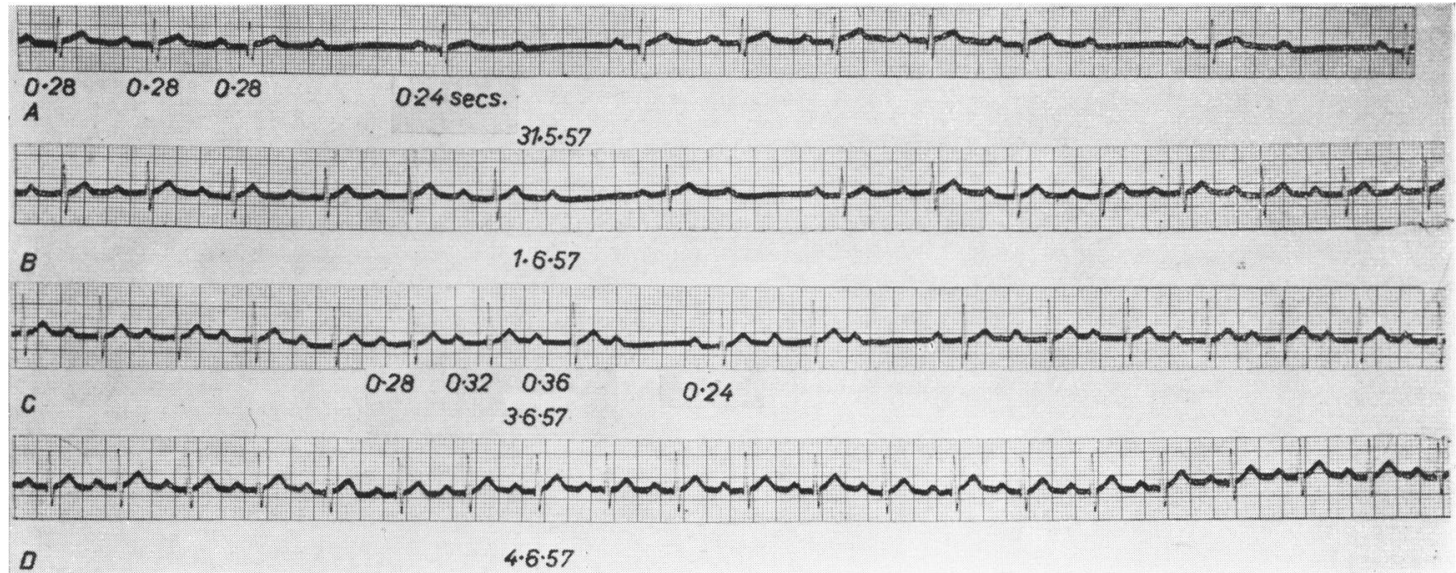

FIg. 2.-Case 2.-Rheumatic carditis on digoxin therapy. All tracings are from standard lead II. Fig. 2a: Mobitz block, constant P-R interval of 0.28 seconds going into a $2: 1$ A.V. block. P-R intervals following dropped beats are shortened to $0 \cdot 24$ sec. Fig. 2 band c: slight variations in P-R interval $0 \cdot 25-0 \cdot 32 \mathrm{sec}$. before dropped beat, i.e. form of varying Wenckebach phenomenon. P-R intervals following dropped beats are shortened to $0.24 \mathrm{sec}$. Fig. $2 \mathrm{~d}$ : normal tracing four days after initial tracing.

were engorged to 2 in. above the sternal angle and the liver was enlarged to three fingerbreadths below the costal margin. The maximum cardiac impulse was located in the 6th intercostal space in the anterior axillary line and was characteristic of left ventricular hypertrophy. A grade III systolic murmur, completely replacing the first heart sound was heard at the mitral area and a blowing diastolic murmur radiating from the base of the heart down the left sternal border was also present. The pulmonary second sound was accentuated and split. All the pulses were palpable, regular in rate and collapsing in quality. The left side of the chest was dull to percussion and there was bronchial breathing over the apex of the left lung.

LABORATORY INVESTIGATIONS. The haemoglobin was $11.5 \mathrm{~g}$. per $100 \mathrm{ml}$. and the E.S.R. was $49 \mathrm{~mm}$. in one hour (Westergren). The $\mathrm{C}$ reactive protein was ++++ . Urine analysis was negative. A radiological examination of the chest showed cardiac enlargement and consolidation of the whole of the left lung. An electrocardiogram demonstrated bifid $P$ waves of left auricular enlargement. The diagnosis was left lobar pneumonia and congestive cardiac failure with established aortic and mitral incompetence.

He received $0.5 \mathrm{mg}$. of digoxin orally followed by three 8-hourly doses of $0.25 \mathrm{mg}$. and a maintenance dose of $0.25 \mathrm{mg}$. daily. In addition he received $1 \mathrm{ml}$. of a mercurial diuretic on alternate days. As improvement was slow, the maintenance dose of digoxin was doubled to $0.25 \mathrm{mg}$. twice daily. Some 28 days later he complained of abdominal pain and vomited. His pulse was found to be irregular and an electrocardiogram (Fig. 3a) revealed a rate of 75 to 100 cycles a minute with well marked sinus arrhythmia. The $P$ waves occurred at regular intervals but bore no relationship to the QRS complexes, showing A-V dissociation.

This dissociation could be temporarily abolished by injecting $0.25 \mathrm{~g}$. of potassium chloride intravenously as is demonstrated in Figs. $3 b$ and $3 c$ which represent the beginning and end of a continuous tracing. A further $0.25 \mathrm{~g}$. of potassium chloride given intravenously produced nodal rhythm (Fig. 3d), which reverted 10 minutes later to A-V dissociation. Fig. 3e taken 18 hours later, and Fig. 3f taken three days later, show a normal tracing with a constant P-R interval of $0 \cdot 14$ seconds.

Case 4. An African child aged 8 years complained of a severe cough, high fever, a stabbing pain in the chest and dyspnoea at rest which commenced 24 hours before admission to hospital.

He was orthopnoeic and the respiratory excursions were obviously limited by pain. The right side of his chest moved poorly on respiration and was dull to percussion. Crepitations, bronchial breathing and diminished air entry were heard over the right base and midzone. The pulse was irregular due to sinus arrhythmia. The heart was not clinically enlarged and a grade II systolic murmur was heard at the mitral area. A diagnosis of right lobar pneumonia was made.

He was treated with 6-hourly intramuscular injections of 500,000 units of penicillin. Two days later the temperature fell to $98^{\circ} \mathrm{F}$. and the pulse rate from 120 to 80 beats a minute. Four days after admission the child was still distressed despite the resolution of the infection. An electrocardiogram at this stage shows a ventricular rate of 60 cycles a minute with A-V dissociation (Figs. 4a, $4 b$ and $4 c$ ). The P-P and P-R intervals varied in length, the $P$ waves being periodically lost in the QRS complexes. The next day (Fig. 4d) the rate was 54 cycles a minute with sinus arrhythmia present. The A-V dissociation had however disappeared and this return to normal rhythm coincided with a marked clinical improvement. 


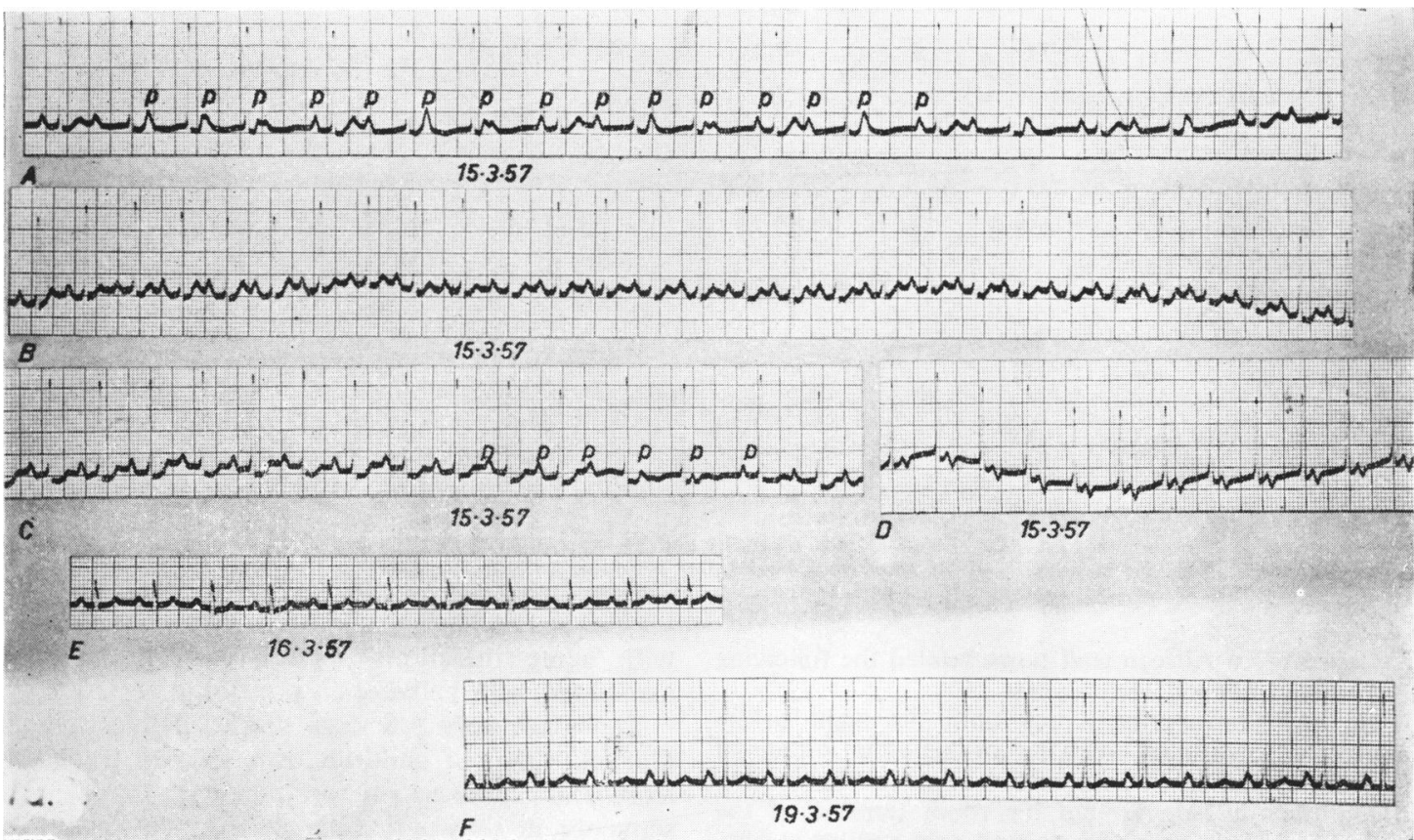

FIg. 3.-Case 3. Rheumatic carditis with left lobar pneumonia. All tracings are from standard lead II. Fig. 3a: constant P-P interval of $0.48 \mathrm{sec}$. with heart rate of 75 to 100 cycles min. P waves bear no relationship to QRS complexes, showing A.V. dissociation. Fig. 3b and $c$ are beginning and end of continuous tracing during intravenous injection of $0.25 \mathrm{~g}$. of potassium chloride showing tachycardia of $136 \mathrm{cycles} / \mathrm{min}$. with abolition of A.V. dissociation which recurs five min. later (Fig. 3c). Fig. 3d: tracing during intravenous injection of further $0.25 \mathrm{~g}$. of potassium chloride showing that nodal rhythm has replaced A.V. dissociation. Fig. 3e and $\mathrm{f}$ : normal tracings 18 hours and two months later.

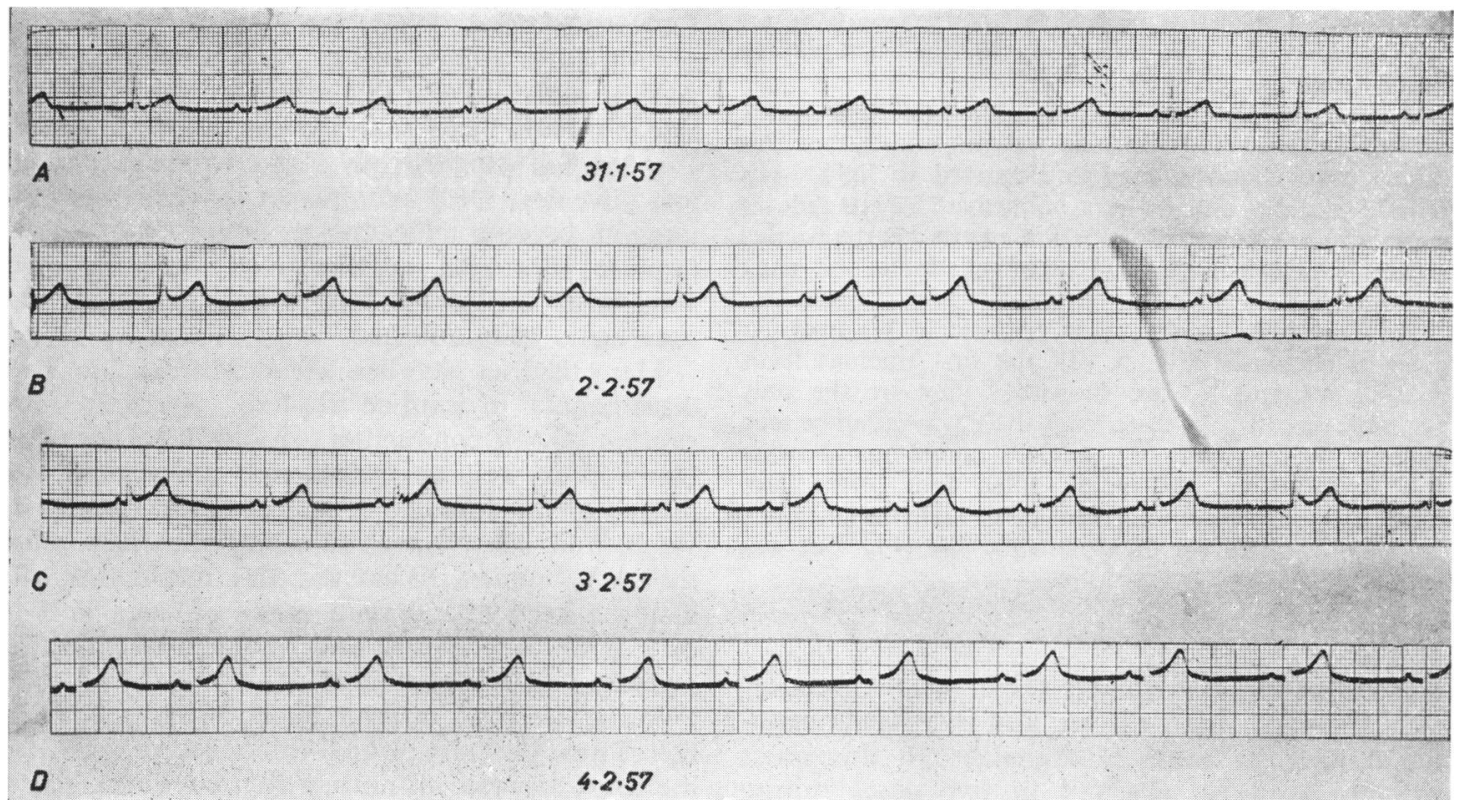

Fig. 4.-Case 4. Lobar pneumonia. All tracings are from standard lead II. Figs. 4a, b and c: sinus arrhythmia with ventricular rate of 60 to 75 cycles/min. P-P intervals vary in length and P waves are periodically lost in QRS complexes. This is tracing of A.V. dissociation. Fig. 4d is tracing taken next day and shows disappearance of A.V. dissociation. 


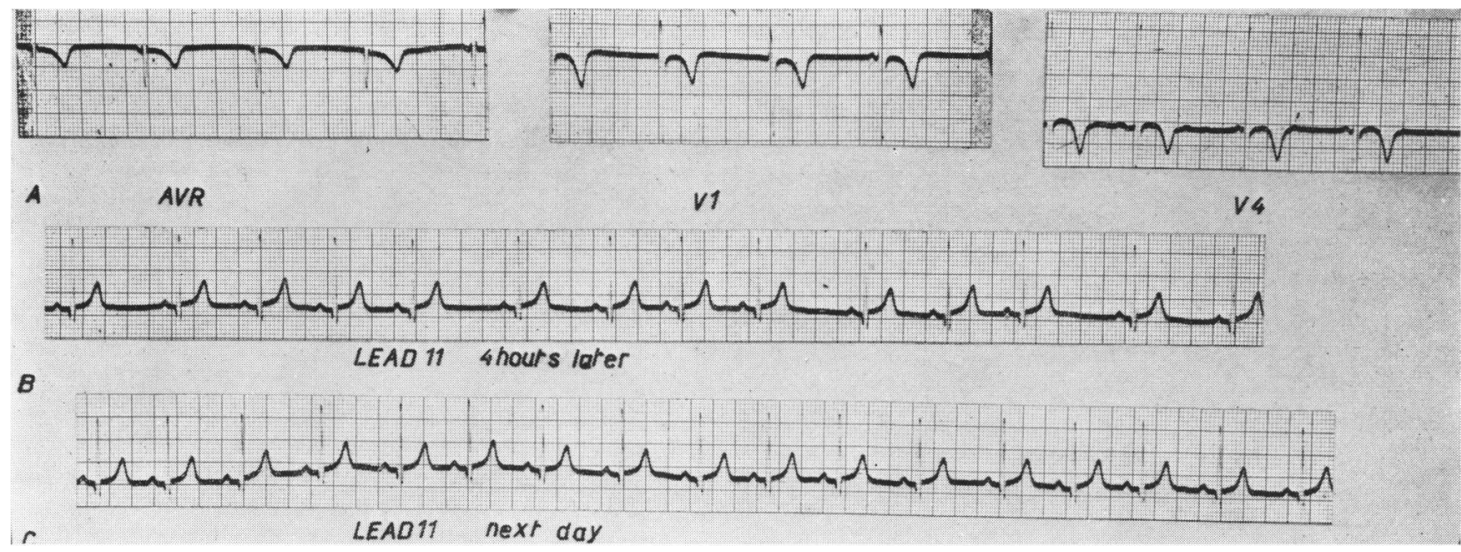

FIg. 5.-Case 5. Belladonna poisoning. Fig. 5a: leads AVR, VI and V4 show A.V. dissociation with $P$ waves moving in and out of QRS complexes. Fig. 5b: standard lead II, taken four hours after preceding tracing and shows A.V. dissociation replaced by sinus arrhythmia. Fig. 5c: standard lead II, normal tracing taken next day.

Case 5. An African staff nurse related the following story about her son aged 8 years.

He had been perfectly well until the night before admission to hospital when he awakened in a state of extreme mental excitement and confusion. His mother found him dashing around his room terrified of the snakes and trains which he claimed were rushing at him. She noticed that he was flushed, his pupils were dilated and his mouth was dry. He had to be strapped down for the night and a doctor called to see him the next day, gave him an intramuscular injection of 'somnifane'. He slept for about three hours and awoke still confused. It was ascertained that he had not had access to drugs but that he might have eaten some berries when playing in the fields.

On examination he was restless, exhibiting quick nervous movements. His skin was hot and flushed, his pupils were widely dilated and reacted to light. His mouth was dry and he was hallucinated. His reflexes were brisk. Clinical examination of the heart revealed no abnormalities and a diagnosis of belladonna poisoning was made.

An electrocardiogram taken because of his irregular pulse is shown in Fig. 5. In the first tracings leads A.V.R., V1 and V4 are shown as they are the only available records. In these leads the $P$ waves can be seen moving in and out of the QRS complexes showing A-V dissociation. A tracing taken four hours later (Fig. 5b) showed well-marked sinus arrhythmia, while the tracing taken on the following day (Fig. 5c) was normal.

\section{Discussion}

In childhood arrhythmias occur most commonly with rheumatic heart disease and in patients maintained on high doses of digitalis. In this series arrhythmias were observed in two cases during digitalis therapy given for cardiac failure following rheumatic carditis, in two cases they were associated with acute infections, while the fifth case was associated with belladonna poisoning.

There are very few case reports (Blumgart and Gargill, 1930) of children who showed transitions from A.V. dissociation to sinus arrhythmia. This sequence is shown in Case 5 (Figs. 5a-c), and was associated with belladonna poisoning.

Blumgart and Gargill (1930) demonstrated a distinct relationship between sinus arrhythmia and A-V dissociation. They showed that when the P-P interval lengthens, shortening of the P-R time results. Extreme prolongation of the P-R interval results in a ventricular escape which may manifest itself as A-V dissociation. In this condition the ventricular rate is usually faster than the auricular rate and the $P$ waves fall progressively closer to and are finally lost in the QRS complexes. When the P-R intervals become sufficiently prolonged, a conducted impulse from the auricles may occur, namely, ventricular capture, before A-V dissociation may once again be established.

Many theories have ben advanced to explain these disturbances in cardiac rhythm. Organic interruption of $\mathrm{A}-\mathrm{V}$ conduction (Mobitz, 1923) has been blamed, as well as exaggerated susceptibility to fatigue of the conducting system (Ehrentheil et al., 1952), and disturbances in conduction just before the A.V. node. Whatever the mechanism, the disturbances in the present series of cases were all of a temporary nature and disappeared when the primary disease was treated.

In the two cases of acute infection and the case of belladonna poisoning which responded to treatment, the heart returned to normal rhythm within one to four days after the primary disease had abated. These children subsequently remained well and 
active. Where the primary disease caused marked cardiac damage as in the two cases of rheumatic fever, the patients remained ill with a poor exercise tolerance. The prognosis in these cases depended upon the primary disease rather than the changes in cardiac rhythm. It was, however, observed that all five cases remained distressed during the periods of arrhythmia despite improvement of the primary condition. Clinical improvement coincided with the disappearance of the abnormal rhythm. It is therefore felt that the presence of such electrocardiographic abnormalities suggests the need for strict bed rest while dealing with the primary disease.

A lesson learnt from these cases is that any child suffering from an acute infection who does not make a good clinical recovery when the infection has abated, warrants an electrocardiographic study.

An attempt was made in Case 3 to abolish or modify the arrhythmia by the intravenous use of potassium chloride. This case and that of belladonna poisoning were the only two which reverted to normal rhythm within the short space of 18 hours.

\section{Summary}

The case histories and electrocardiograms of five children showing disturbances in cardiac rhythm are described. Three children showed A-V dissociation and two demonstrated the Wenckebach phenomenon.

Case descriptions of cardiac arrhythmias in children are rare. Those records appearing in the literature are associated with rheumatic fever, digitalis poisoning and diphtheria.

The prognosis in these cases is related to the primary condition rather than to the electrocardiographic findings.

The suggestion is put forward that cardiac arrhythmias in children should be treated by careful nursing and bed rest.

My thanks are due to Dr. I. Frack, the superintendent of Baragwanath Hospital for permission to publish these case records and to Dr. E. Kahn and Dr. S. Wayburne in whose wards these cases were treated. I am indebted to Dr. L. Schamroth for his valuable help and criticism and to Dr. A. Barnett and Dr. J. Theunissen who helped in the investigations of Cases 2 and 3 . I am indebted for the photographs of the electrocardiograms to $\mathrm{Mr}$. Schewitz of the Witwatersrand Medical School.

REFERENCES

Blumgart, Herman L. and Gargill, Samuel L. (1930). Amer. Heart J., 5, 437.

Ehrentheil, Otto F.. Alimurung, M. M. and Massell, B. F. (1952) Amer. Heart J., 43, 228.

Kuhn, Leslie A., Donoso, Efraim and Sapin, Samuel O. (1954). Ibid., 48, 280 .

Langen, C. D de (1956). Cardiologia (Basel), 29, 77.

Lemann, I. (1953). Ann. intern. Med., 7, 779.

Magri, G. (1953). Acta cardiol. (Brux.), 8, 529

Mobitz, W. (1923). Dtsch. Arch. klin. Med., 141, 257.

Sprague, Howard B. and White, Paul D. (1927). Med.Clin. N. Amer. 10, 1235

Wood, Paul (1956). Diseases of the Heart and Circulation, 2nd ed., p. 222. London

Wenckebach, K. F. (1899). Zeitschr. f. klin. Med., 37, 475.

- - (1906). Arch. Anat. Physiol., Lpz.. 30, 297.

Zimdahl, W. T. (1951). Amer. Heart J.. 41. 204. 